\title{
The bicycle at the end of the 19th century: An instrument for land surveying and mapping
}

\author{
Tristan Thielmann ${ }^{\mathrm{a}}$ \\ ${ }^{a}$ University of Siegen, tristan.thielmann@uni-siegen.de
}

\begin{abstract}
At the end of the $19^{\text {th }}$ century, the bicycle was a medium used for land development, connection, sensing and routing. This article explores these features of the bicycle based on the League of American Wheelmen bulletins that were published between 1880 and 1902. The enquiry shows that the bicycle constitutes a rural geomedium since the first cyclists regarded themselves as land surveyors. Furthermore, the bicycle, as a vehicle that is connected to an individual, links the starting and end points of a route - without stops on the way and without changing vehicles. This continuity of movement is a highly essential property of the medium 'bicycle'. Being awheel and making the countryside accessible cartographically are therefore closely linked to each other; they take place in one and the same procedure as part of the joint practice of land surveys. During this process, the bicycle proves to be an ideal instrument for the sensing of road surface conditions and therefore functions as a mediator between the road and the cyclist. It also serves as a mediator between urban and rural areas and as a connected device: the bicycle is the condition for cooperation for Bicycle Clubs, which enjoyed enormous popularity at the end of the $19^{\text {th }}$ century. It facilitated the cooperative experiencing and exploring of the land that had yet not been documented cartographically and, in turn, yielded its own new form of representation: navigable maps in the form of route guides.
\end{abstract}

Keywords: rural geomedia, navigable maps, route guides, land surveyors, League of American Wheelmen

\section{Introduction}

The bicycle is a medium sui generis if we base this on the expanded meaning of the term medium, as was primarily represented and made popular by Marshall McLuhan ( $c f$. McLuhan 1992). ${ }^{1}$ According to McLuhan, the invention of the wheel already led humans to react to the excess load placed on the feet through faster trade and transport (cf. ibid., 58). The bicycle then certainly constitutes an extension to the body within the meaning of McLuhan. The history of science and technology also describes the bicycle as a central actor and mediator of sociotechnological change ( $c f$. Bijker 1997). It was already regarded as an "earth-friendly machine" in the $19^{\text {th }}$ century (Norcliffe 2001, 15). Even so, it may initially appear surprising that the bicycle can be outlined as a rural geomedium. At first glance, at this time, the bicycle seems to develop its specific characteristics in rather more urban contexts ( $c f$. Friss 2015). However, the historical analysis given below reveals a different picture. The bicycle was not an "appendage of the mass media located in cities" (Zimmermann/Mahlerwein/Maldener 2018). The bicycle only became a medium through its "connection to the land". On the one hand, there are many medial representations in the popular magazines of the time, showing bicycles stuck in the mud of unsurfaced country roads ( $c f$. Figure

1 Conversely, the question of-as, for example, for Jean Baudrillard - whether the road is also a medium, will not be pursued any further here. $c f$. Münker/Rösler 2008, 11.
1). These photographs were taken at the end of the $19^{\text {th }}$ Century to epitomize the importance of surfaced roads to the rural population.

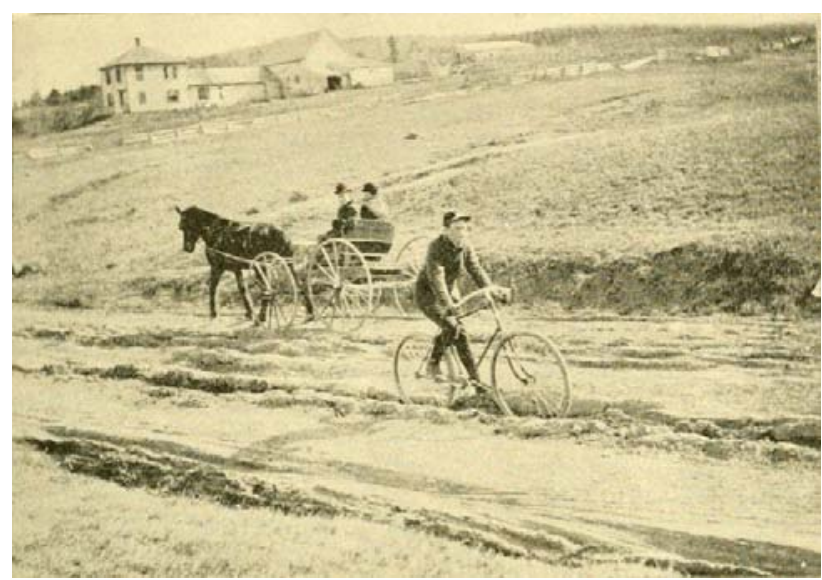

Figure 1. A photograph of a road in Washington County, Maine, USA, sent to the Good Roads magazine. Source: N. N. 1894.

On the other hand, the bicycle served the purpose of establishing translocality, namely, (a) through the connection of town and country, (b) through local connections to other modes of transport and between settlements and (c) through the opening up of unknown terrain. Furthermore, the bicycle itself engendered geographical representations in the form of maps and a system of signage and signposts. In this sense, we can discern that the bicycle represents, transforms and produces geographies. The bicycle therefore fulfills all conditions that are de- 
manded of a rural geomedium, even now, under digital conditions ( $c f$. Ash/Kitchin/Leszcynski 2018).

\section{Background for analysis}

To date, initial approaches have been taken in the scientific literature toward conducting research into the cultural and social geography of cycling, especially also under consideration of gender-related aspects ( $c f$. Norcliffe 2015). However, these investigations do not consider the bicycle in terms of rural exploration. While the social, cultural and technological history of the bicycle has already taken on different forms ( $c f$. Smith 1972; Dauncey 2012; Guroff 2016; Lessing 2017), a history is missing that analyzes the cycling magazines of that era and evaluates these with a particular focus on the reconstruction of the transport, traffic and media practices at the end of the 19 th century.

In the USA, the bicycle was therefore a disruptive technology right from the start, which not only challenged the development of infrastructure at the time, but also simultaneously founded a new social movement. Shortly after Colonel Albert A. Pope acquired one of the first US bicycles in 1878, he set up the Boston Bicycle Club, initially simply to meet up with others for cycling races. Only one year later, there were already 49 bicycle clubs in the USA, which combined to form a national organization in 1880: the League of American Wheelmen, mainly made up of white males from the elite of society. ${ }^{2}$ The alliance of the L.A.W. had set itself four objectives: (a) to advertise cycling, (b) to represent the rights of cyclists, (c) to promote bicycle touring, (d) to improve the roads (Quinn 1968, 2 et seq.).

The analysis that follows is based on a sequential evaluation of all magazines published by the League of American Wheelmen between 1880 and 1902. These magazines constitute a relevant object of research in that they not only served as a national means of information and advertising, but were also the official mouthpiece of the $L . A . W$. The virulent importance of the bicycle as a rural medium is clear based on different letters from readers and reports made by members of the alliance. From 1880 onwards, the League of American Wheelmen issued the L. A. W. Bulletin on a weekly basis, which was published in collaboration with other cycling magazines. This bulletin appeared in the magazine The Wheel from 1880 onwards, was briefly independent in 1888, as of 1888 it was published jointly with the magazine The Bicycling World, as of 1892 jointly with the magazine Good Roads and as part of Elliott's Magazine from 1898 onwards. Good Roads was a magazine that was initially also produced by the League of American Wheelmen, the responsibility for which was then passed on to others in 1896. The Good Roads Magazine was the official mouth-

\footnotetext{
${ }^{2}$ At that time, cycling was the preserve of, e.g., doctors, lawyers, teachers, businessmen and women or employees who could afford a bicycle ( $c f$. Friss 2015, 42). Not all local subdivisions of the League of American Wheelmen accepted women as members ( $c f$. Dando 2018). Black people were denied membership ( $c f$. Friss 2015, 58-61).
}

piece of the League of American Wheelmen up to 1902. This is why the period covered by this investigation ends at this point in time. After this, the social and infrastructural importance of the bicycle waned. At the beginning of 1902, the League of American Wheelmen had fewer than 1,000 members ( $c f$. League of American Wheelmen Official Department 1902, 25); at its height in 1898, there were approx. 103,000 members ( $c f$. Friss 2015, 188). All contents of these magazines (including maps, photographs and advertisements that were published) were inspected and evaluated. Based on this evaluation, this contribution aims to reveal the historical importance of the bicycle as a means for rural exploration, navigation, surveys and connectivity.

\section{Following traces}

The historiography of cycling routes in the late $19^{\text {th }}$ century faces the challenge of following the narrow, finely branched paths on which the cyclists traveled, based on the traces that have been recorded, can be reconstructed and are still found.

\begin{abstract}
"Rather than beaten trails through wild or unknown regions, however, those narrow, tire-worn passages instead signal the start of searches through a different type of uncharted terrain: the urban, suburban, and rural locales where bicycles can function safely, both as vehicles for recreation and as a means of transportation. Charting a course for those investigations, or taking one's trace, is as uncertain today as it was a century ago." (McCullough 2015, xii)
\end{abstract}

The maps of the time were generally no great help as their scale was too large to find the right route ( $c f$. Osborne 1899a, 101). A new method of traveling across the land was to cycle in the wagon tracks ( $c f$. Figure 1). Socalled "soft roads" that were composed of sand or clay were almost impassable with narrow wheels, apart from during frost. It was therefore quite common and in the interests of the coachmen to broaden the wheels of coaches, covered wagons, etc.; these were sometimes six inches wide.

\footnotetext{
"These tires had made the county roads where they had traveled almost like a pavement, and he found the owner of the wagon could haul heavy loads with such tires when the roads were in bad condition. On soft roads where the tires had gone over, it made it an easy matter for cyclists to spin over the country." (Quinn 1968, 20)
}

It was thus initially quite common for cyclists to follow in the tracks of other means of transport. For example, the corridors between railroad tracks and paths alongside were also used as rural roads ( $c f$. McCullough 2015, 108), as is demonstrated by the following advertisement of the National Cycling Manufacturing Company (cf. Figure 2). This method increased the probability of reaching the planned destination, or a destination, even on unknown terrain. A particular challenge faced in countryside was the paucity of orientation points that were close enough together for bicycle navigation. The field notes made by the individual local cycling club members often recorded 
places that were mainly known to cyclists who rode systems that indicated the route were therefore essential to travelers who were unfamiliar with the location.

\section{NATIONAL BICYCLES}

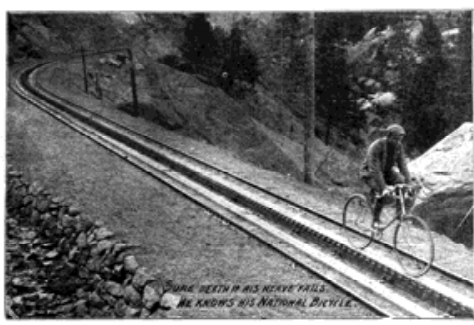
around locally ( $c f$. ibid. 4). Publicly accessible signage

in a pocket: "With the stencil plate in your pocket you may organize a business or a pleasure trip on your wheel, making out the safest and best routes to the tourist or uninformed, as you go" (ibid.). This ease of transport aimed to encourage members of the League of American Wheelmen to affix the signs to fences, trees and notice boards - i.e., in locations were people unfamiliar with the location might search for guidance (cf. Quinn 1968, 19). However, the signage was not something that arose spontaneously during travel; rather more, the route had to be cycled along at least twice and the paint and stencils had to be taken along.

The stencil signs were uniform in design. They contained the League of American Wheelmen logo, which aimed to serve as both a quality attribute and simultaneously for advertising purposes (N. N. 1882a). The next figure shows the first version of the signage system used by the League of American Wheelmen (cf. Figure 3). The most commonly used signs were the first three, while signs four to eleven were optional. ${ }^{3}$
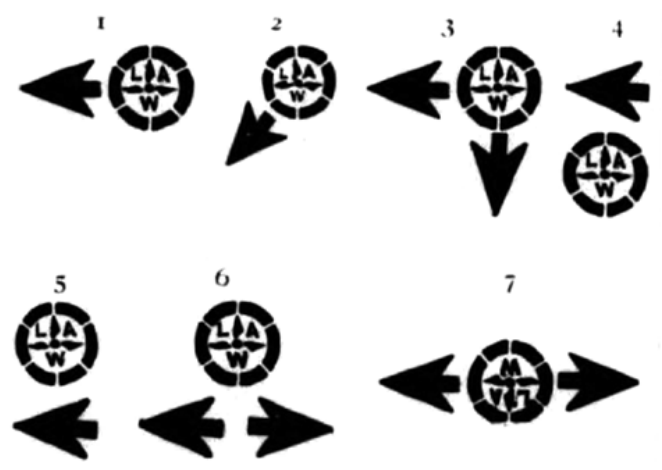

(cf. Quinn 1968, 19). There was neither a road designation system, nor mapping suitable for navigation, and the L. A. W. therefore came up with the idea, very early on, of signposting routes with way markers and stencil signs, also called sign boards. In the case of the latter, these were small notice boards that wheelmen fixed along the side of roads from 1883 onwards ( $c f$. J. W. 1881).

An 1883 issue of The Wheel gives the first information on the signage process and the function of the way markers. Given that rural roads were in poor condition, the signage system was to provide information on how passable the route was and the direction to be taken, to ensure that cyclists followed the designated route and thus reached their destination: "They [the sign boards] tend to increase the confidence of a traveller traversing an unfamiliar road, enliven and stimulate a tired and worn traveller" (N. N. 1882a). Furthermore, cyclists were to be encouraged to cover longer distances and to explore the area (cf. ibid.).

The cyclists signposted the roads themselves by taking stencil plates with them, which members of the League of American Wheelmen could obtain by post and use to affix markings at relevant locations like crossroads or sections of the route that were poorly passable ( $c f$. Beckwith 1883a). The signs that were painted using the stencils were to be affixed to the right side of the route, but always in consultation with the proprietors of the roads.

The stencil signs were designed to suit the cyclists' mode of travel and were therefore easy to take with them

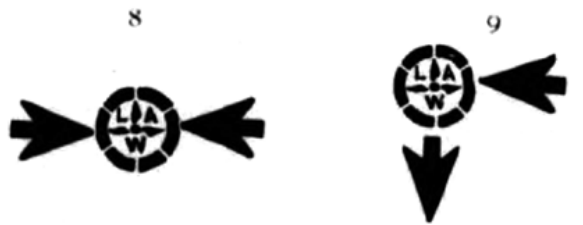

Figure 3. The L. A. W. stencil signs in 1883. Source: N. N 1883.

The use of this first form of road signage shows how the cyclists helped themselves by developing markings that were adapted to their mode of travel and were designed to facilitate cycling and getting one's bearings in rural areas. The bicycle itself and the aids that were taken along to designate and mark the environment created their own form of semiotic agency on location and in situ. After 1887, traces of the stencil signs are lost in the League of American Wheelmen magazines.

Instead of this, with the advent of cycling routes in the 1890 's, which is entered into in the next section, members of the L. A. W. started to put up metal signposts instead ( $c f$. Figure 4). These aimed to help cyclists with

\footnotetext{
${ }^{3}$ The signs no. 10 and no. 11 were not printed in this issue of The Wheel. Reference is made to 18 of these stencil signs at a different location in The Wheel.
} 
their orientation at crossroads and forks in the road and to warn them of any hazards.
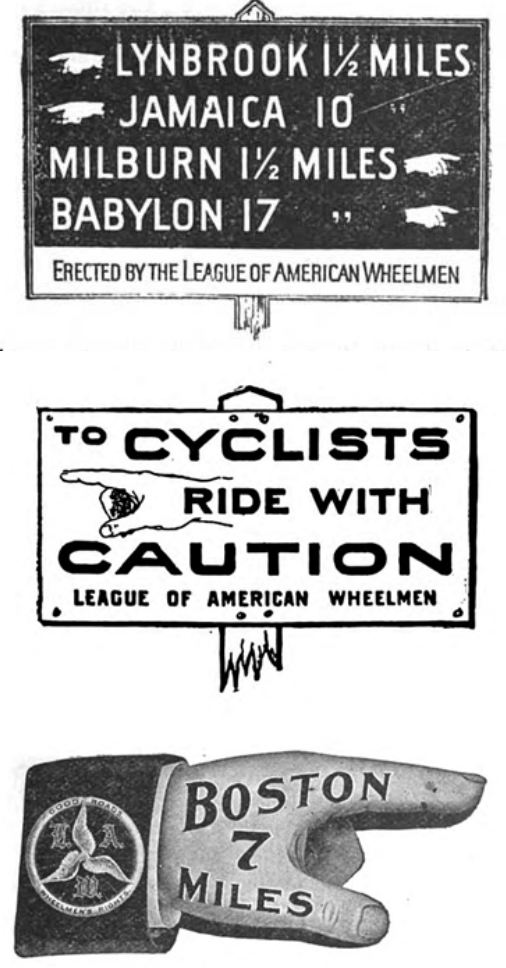

THE HELPING HAND.

Figure 4. League of American Wheelmen information signs. Source: Potter 1898, 65-67.

\section{Traveling along byways}

Farmers and politics at the end of the $19^{\text {th }}$ century made very little effort to expand the infrastructure, while individual divisions of the League of American Wheelmen were already starting to build their own cycling routes, which they called "side paths" or "cycle paths":

\footnotetext{
"But while we are waiting for the action of the state and the farmers we are quietly building some good roads of our own, which we call 'side paths', and it's because we believe that many wheelmen in other sections are circumstanced in the same manner that we are, that we call attention to the work that we are doing." (Raymond 1894, 263)
}

The cycle paths not only aimed to raise public awareness of the work carried out by the $L . A$. W., but were also designed to lay down a marker in protest against the poor roads ( $c f$. Potter 1898, 4). In addition, the construction of these paths aimed to take into account the importance and specific nature of the bicycle. Isaac B. Potter, the president of the League of American Wheelmen at the time, wrote the following on this point in a book on cycle paths: "I venture the assertion that three-fourths of the country know nothing of the full utility of the bicycle" (ibid., 6). Through these cycle paths, cyclists were finally being given a measure of independence from the poor roads and could therefore also demonstrate to other road users that the expansion of the infrastructure would not only benefit them, but was in the general public interest.
The cycle paths thus also served the purpose of demonstrating how traffic could be changed simply by the expansion of roads ( $c f$. ibid. 5 et seq.): "Now we are looking to the cycle path as an object lesson. When the farmer sees the cycler riding easily on the path, while his team is stuck in the mud, his eyes will be opened" (Bassett 1899a). The expectation of a rural 'experience of awakening' was therefore associated with cycle paths. Following this, Cycle Path Associations were founded in many federal states, which built cycle paths using funds from donations (cf. Bassett 1899). The Coney Island Cycle Path, built in 1894 and opened in June 1895 and very popular with cyclists, was particularly potent in terms of its planning and symbolism (cf. Consul No. 67 1899; Friss 2015, 102 et seq.; McCullough 2015, 220232). Ten years before, however, construction of cycle paths had already started for country riding. For example, an ash cycle path network was created in 1885 in Pennsylvania's Luzerne County, the mapping of which will be entered into later on in this article ( $c f$. McCullough 2015, 109). Ideas for cycle bridges were also developed to make cycling more comfortable and to compensate for steep slopes or inclines. A later project in 1899, that was not implemented, is the cycle path from Pasadena to Los Angeles over a distance of nine miles. This was to be built as a wooden construction on stilts, instead of on the ground, and was to go past a casino built exclusively for the cyclists and also past a bicycle club house ( $c f$. Figure 5; N. N. 1899).

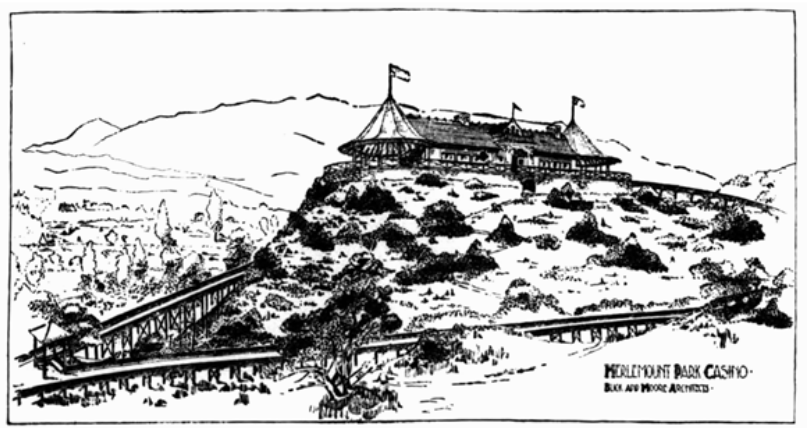

Figure 5. Planned cycle path from Pasadena to Los Angeles by the Merlemount Park Casino 1899. Source: N. N. 1899, 17.

However, the first cycle paths were generally not only characterized by particularly creative forms of construction, as larger distances were also to be covered-once again emphasizing that the bicycle was clearly also intended for long-distance transport. For example, the Bicycle Path Association planned a cycle path in Michigan that would have crossed the entire federal state from North to South. The bicycle was also a mode of transport that was simultaneously conceived as part of a network, namely, joined together with ships and trains, to cover longer distances ( $c f$. Friss 2015, 121). In relation to the construction of the cycle paths, it must be stated that smaller paths and trails frequently already existed in addition to the roads, but these were generally impassable. For example, such paths were used as cycle paths by the Wheelmen of Niagara County. Members of the League of American Wheelmen improved their condition, such that they could be used running parallel to the roads: "The 
pleasure derived from the use of these natural side paths induced a few of us to believe that by little organization and systematic work, we should be able to build side paths along the bad roads [...]" (Raymond 1894, 263). The cyclists even dreamed of the creation of an own network in the future, through the expansion and linking of individual cycle paths. The surface material was composed of ash, ballast or gravel, which was spread on a hard, rolled substratum. However, there were ditches either side of the cycle paths to prevent farmers from using the cycle paths when the roads were impassable ( $c f$. ibid. 264 et seq.). This led to the development over time of very different travel corridors for cyclists, both within and outside cities:

\begin{abstract}
"Sometimes they ran along the side of the road (thus commonly referred to as side paths) either between the sidewalks and the main road, beyond the sidewalks, or in place of sidewalks altogether. Some cities laid paths in the center of the roadway or in what may have been a grassy strip between two boulevards. In other places, the paths went where streets did not." (Friss 2015, 101)
\end{abstract}

The cycle paths built by the League of American Wheelmen were progressively used more frequently by automobiles at the start of the $20^{\text {th }}$ century, before they gave way to wider roads and disappeared under asphalt ( $c f$. Guroff 2016, 62 et seq.). Cycle paths thus formed the basis of the road network that still exists today in the USA ( $c f$. Reid 2015). They constitute a latent infrastructure that made an essential contribution toward the transport infrastructure of today, in that the actor network composed of the bicycle, cyclist and paths took possession of the methods of spatial extension and expansion.

\section{Land surveying}

The bicycle played an important role in the construction and expansion of roads. ${ }^{4}$ In its guise as an instrument of cartography, it served the purpose of evaluating the state of the roads, on the one hand, and of developing navigational aids, on the other. With the help of the L.A.W. Bulletin, which functioned as a communication platform for the members of the League of American Wheelmen, cyclists drew attention to the central infrastructural problems already described above: the poor state of the roads and the lack of signage. In addition to the stencil signs, the individual divisions of the $L . A . W$. therefore also produced and published different forms of route guides, so-called road books, from 1884 onwards, up to at least $1899 .^{5}$

The League of American Wheelmen discovered the practice of mapping through the practice of cycling. The members of the $L . A . W$. were therefore a network of amateur cartographers who jointly negotiated the process

\footnotetext{
${ }^{4}$ At the time, the notion prevailed that bicycles with pneumatic tires functioned as street rollers and were therefore themselves a cost-effective aid in road construction $(c f . \mathrm{N}$. N. 1902).

${ }^{5}$ An incomplete selection of the road books can be found in: McCullough 2015, 354.
}

of developing the navigational medium, the cycle map. This process can be reconstructed through the conduct of historical research on the different $L . A$. W. Bulletins. The road books produced by the members of the L. A. W. were compiled based on voluntary work. The cyclists combined their enjoyment of travel with documenting the state of the roads, from which all members ultimately benefited. Only a few instruments were required for this documentation, all of which were unified with the medium of the bicycle or could be attached to it: a pennyfarthing (from 1888 onwards, succeeded by a safety bicycle, which was similar to today's bicycle) with a cyclometer to measure the distances covered, as well as a $\log$ book and writing materials ( $c f$. Figure 6$)$.

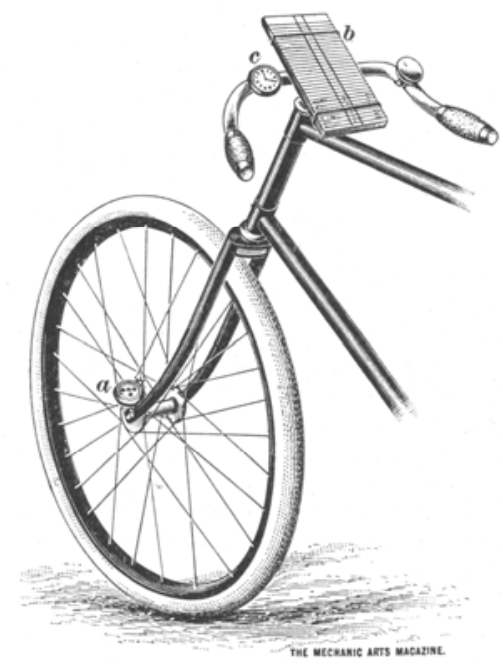

Figure 6. Bicycle with a cyclometer and watch fixed to the handlebars, as well as a note book for rural exploration. Source: Osborne 1899a, 102.

An 1881 issue of The Wheel already contains a reference to a log book that was being produced for cyclists, in which they could note the names of places, distance covered, state of the roads and take other notes during their tours. The recording and documentation of the road conditions were of particular importance. This was carried out by the cyclist riding along the roads and then subsequently rating them. The cyclist documented his notes on the route in this $\log$ book, which initially served as a private route diary: "Our bicycling friends, on turning over its pages at the end of the season, will thereby recall many pleasant events" (N. N. 1881). However, in 1882, a proposal was also put forward, stating that the information in the private route diaries could be re-used in the production of road book for the USA: "If all bicyclers could be prevailed upon to keep an accurate log of their riding, we might have a first class 'road-book' of the States for use in touring" (N. N. 1882b).

As of 1882, the distribution of route slips was started, to collect information on routes, road conditions and hotels ( $c f$. Telzah 1882, 85). The route slips were sent to members of the $L$. A. W. and were to be completed during the cycling season. The data were then sent to the delegate of the local division, who collected and analyzed the route slips completed by all members ( $c f$. Beckwith 
1883b). The road books that were produced based on these route slips contained all information noted down by the cyclists (above all, information on slopes was also important here). The road books were initially compiled in tabular form, based on the design of the route slips. Maps only became established later on. This was mainly due to the fact that the unsurfaced roads did not permit unambiguous mapping as their topographical course was often unclear and the strongly weather-dependent state of the roads frequently compelled cyclists to employ muddling-through techniques and repeatedly use new routes (cf. Thielmann 2016, 178 et seq.).

Road maps could also be compiled without reference to a topographical map, using a method developed by Louis Allen Osbourne, whereby cyclists, themselves, became land surveyors:

"Now every man who rides a bicycle, and has attached to it a cyclometer that registers the distance traveled, possesses sufficient instruments to measure and lay out a map of the country over which he travels, and thus, should he so desire, to make a surveyor of himself." (Osborne $1899 b, 124)$

This geodetic method essentially only required a means of transport (bicycle), a device for measuring distance (cyclometer) and a medium for recording data (note book). A so-called 'cycling watch' was now sometimes also being used ( $c f$. Figure 6 ) to record the intervals between turning points and to thereby illustrate the distance covered relative to the time taken. This allowed indirect statements to be made on the quality of the road and on the elevation profile ( $c f$. Osborne 1899a, 103 et seq.). The data was collected by mobile groups, on the move, which is why the assumption was made that the individual cyclist could not simply stop to make individual measurements ( $c f$. ibid., 102). To implement these 'measures', two vertical, parallel lines, representing the road from the subjective perspective of the cyclist, were drawn in the middle of the small pad for stenographic notes ( $c f$. Figure 7). The stenography pad was fixed to a wooden board with rubber bands which, in turn, was attached to the handlebars of the bicycle. This allowed the cyclist to makes notes and observations while riding along, without having to get off the bicycle. The direction in which the cyclist turned off was entered in the middle, based on the distance that had been covered, and the relevant land marks were noted on the left, which were to serve the purpose of helping subsequent users of the 'cycling map' with their orientation.

"If the bicycle surveyor be an experienced rider, his map may be so plotted, that grades and conditions of road may be readily expressed, and other information never found on the most accurate maps may be added as a guide for the future traveller." (Osborne 1899b, 124)

There was thus clearly great confidence in the skill of the cyclists at this time. They were thought capable of riding over unfamiliar terrain at the same time as documenting it on paper. Osborne saw the advantages of this real-time mapping in the specific (selective) attentiveness that arose during cycling and the sense of adventure associat- ed with cycling, which thus manifested in the cartographic illustration.

\begin{abstract}
"Thus, a complete and satisfactory survey of the road may be plotted in an hour, from notes which were taken without the slightest loss of time on the trip. The bicyclist is rendered more observing by work of this character, he sees every detail, he notes every bend in the road, and in a short time he unconsciously searches for some landmark, by which he can identify a certain piece of road [...]." (ibid., 127)
\end{abstract}

Individual psychogeographies of rural space were thus produced. The amateurish cartographic experiments carried out by the first cyclists resulted in the first mobile route guides with instructions for navigation. At the end of the $19^{\text {th }}$ century, the rural medium of the bicycle thus created an orientation and navigation system from a firstperson perspective, which was developed by and for technical media. This mobile stenographic method, however, only served as an interim step for the transcription into a classic cartographic representation ( $c f$. Figure 8) which, in turn, had to be translated in situ (conceptually and spatially) for use in navigation.

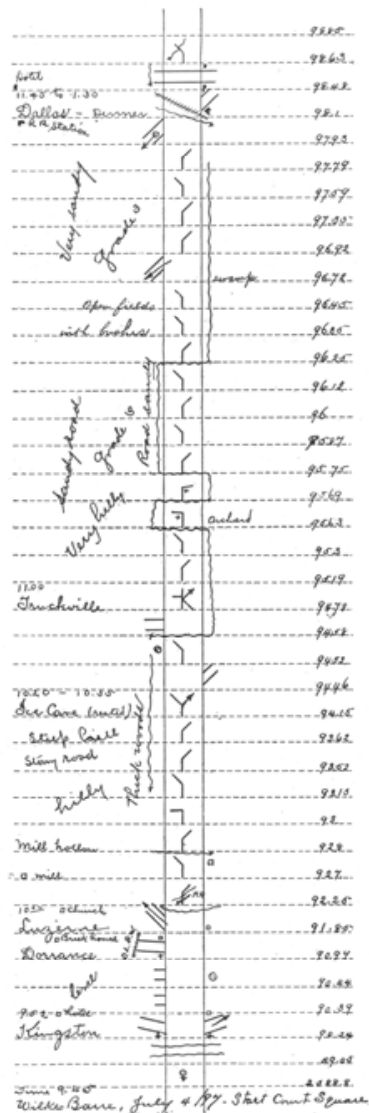

Figure 7. Route mapped with the bicycle on $4^{\text {th }}$ July 1897 by Wilkes-Barre, through Dallas to Shawanese, with information on turning points and distance data. Source: Osborne 1899a, 103.

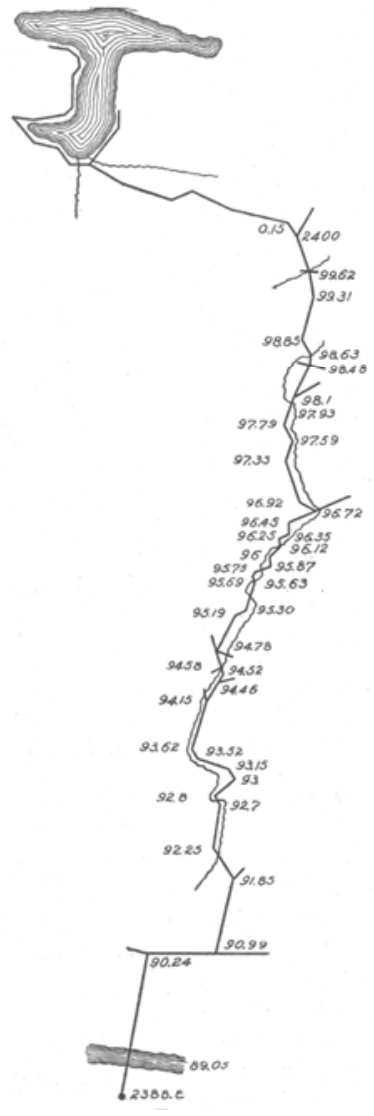

Figure 8. Reconstruction of the route covered by WilkesBarre to Shawanese in Pennsylvania, scale 1:63360 Source: Osborne 1899a, 104.
The mobile recording method also contained estimates of the angle at turnings. Slight bends were not documented during travel. When a bend or turning was not right- 
angled, the greater or lesser angle was indicated with a plus or minus sign. In addition, notes were made on whether the route was on the left or right of the course of a river (if present). Critical decisions on the direction that needs to be taken are easily read off the route sketch. These are marked by dashes that deviate to the left or right from the predefined parallel lines. All marks that are within the two parallel lines thus show that the rider is on the correct course; all marks outside the two parallel lines represent decisions that need to be taken on the direction or indicate relevant additional information on, e.g., places, landmarks or slopes/inclines. This created a set of tools that could be used to map unfamiliar terrain in a short time, such that it contained the information essential to cyclists. For the first time in history, bicycle mapping thus visualizes the fact that quite different recording media and depictions of the surroundings are of relevance during movement, in comparison to under static conditions. This mobile, space and situation-related coding method served as a 'program' for producing a variety of printouts (printed maps).

\section{Conclusions}

"The wheelmen is the land-mariner, so to speak; and he may well be a geographer, a geologist, a naturalist, a cartographer, etc., and add much to his pleasure thereby." (Pratt 1894)

At the end of the $19^{\text {th }}$ century, the bicycle was a medium for rural development in multiple ways. It can be called a rural medium for no more than the simple reason that the first cyclists viewed themselves as land surveyors. In addition, it links the starting and end points of a connecting route as an individual medium-without stops and changes on the way. This uninterruptedness of movement becomes a very important characteristic of the medium bicycle.

"[...] the bicyclist is out on a trip with a number of other enthusiasts, and, therefore, will be unable to stop and make any individual measurements of the roads and landmarks he passes. All notes must be made awheel, and information recorded without slackening speed." (Osborne $1899 b, 126)$

The rural experience and the cartographic rendering of this experience are therefore closely linked to each other; they took place as part of a common practice of land exploration through one and the same method. In this process, the bicycle proved to be the perfect instrument for documenting the condition of the roads. If horses could talk, wrote Lewis J. Bates in The Wheelman in 1882, they would complain about the bad conditions for traveling on roads in the USA, just like the cyclists ( $c f$. Bates 1882). The bicycle can therefore be understood as an instrument of communication, which provided and provides insights into the state of the roads:

"Of all modern inventions the bicycle may most justly be styled the perfect road tester. From no other vehicle does a rider descend with so much suddenness and aplomb, and with such serious emotion, to investigate a defect in the surface of the highway. It is the most sensitive of all vehicles to the slightest imperfections of any sort in the construction or condition of a road surface; and it communicates its discoveries to its rider directly, and in a manner which it is impossible to either ignore or forget. One who lolls in his carriage does not appreciate the effect upon his horses of a trifle of sand over the surface of a road, an unnecessarily steep grade, the roughness of a pavement which ought to be smooth, mud, stones, ruts, dim lights, wet paving blocks, slippery clay, icy streets, and other such evils. The jars, tremors, shocks, sudden strains, abrupt jerks and pushes, which worry the spirits and exhaust the strength and speed of his team and wear out his vehicle, do not affect his own person much. He knows them only through observation. The bicycle rider, on the contrary, experiences all these evils in his own muscular and nervous system." (ibid.)

The bicycle served as a connecting link between the road and the rider. It can be described as a communication medium as it (a) inevitably and unavoidably communicates and as it (b) amplifies the road-related information and transmits it directly to the human nervous system. The indispensable communicative form 'necessarily' makes the bicycle into a medium that could also not be replaced by alternative instruments. Furthermore, it served as a connecting link and "distance destroyer" (Friss 2015, 120) between town and country, as well as an affiliating element within a social network. The bicycle was the cooperative condition for bicycle clubs that enjoyed enormous popularity at the end of the $19^{\text {th }}$ century. These were characterized by a strong cohesiveness, far more so than many other social activities of that era. "From the beginning of bicycling the Wheelmen showed a disposition to get together, creating a fraternal feeling not seen in many other clubs" (Quinn 1968, 3). The bicycle facilitated the joint experience and exploration of the country that had not yet been mapped and, in turn, yielded its own, new form of representation: navigable maps in the form of route guides.

In this sense, the bicycle can therefore also be described as a rural medium as it was the technology carrier for an entire series of infrastructural developments, in particular, the conquest of the public space through signage systems (traffic signs) and road networks. The bicycle was more reliant on good roads than any other means of transport of that time. Its success was therefore inherently linked to the infrastructural conditions. In itself, this is not unusual for means of transport. However, unlike a horse and its rider, the bicycle was the first individual medium that was dependent on an infrastructure that covered as much area as possible - in this case, a paved road network.

Cycle paths and cyclists not only linked town and country in the form of a communicative (permanent) connection, but also facilitated access into the most isolated of rural areas. Hence, the media specificities of the bicycle include the development of a finely and extensively branched transport infrastructure in the form of a network, just as, conversely, the infrastructural network of paved roads created the demand for environmentally friendly means of transport with a long range ( $c f$. Friss 
$2015,99)$. The bicycle was thus the trailblazer for a new transport culture involving people, artifacts and signs. In its guise as a mobile and simultaneously rural medium, its importance is not to be underestimated, when compared to telegraphy and telephony.

\section{References}

Ash, J., Kitchin, R. and Leszcynski, A. (2018). Digital Turn, Digital Geographies?, in: Progress in Human Geography 42/1, pp. 25-43, first published online: 24.08.2016, https://doi.org/10.1177/0309132516664800 (09.04.2019).

Bassett, A. (1899a). The Secretary's Page, in: L. A. W. Bulletin and Good Roads 29/8, 24.02.1899, p. 270.

Bassett, A. (1899b). The Secretary's Page, in: Good Roads 39/9, 03.03.1899, p. 316.

Bates, L. J. (1882). The Effect of the Bicycle Upon Our Highway Laws, in: The Wheelman 1/1 (October 1882), p. 41.

Beckwith, N. M. (1883a). New York L. A. W. Consuls, in: The Wheel 4/3, 20.04.1883, p. 6.

Beckwith, N. M. (1883b). To New York State Consuls, in: The Wheel 4/15, 13.07.1883, p. 4.

Bijker, W. E. (1997). Of Bicycles, Bakelites, and Bulbs: Toward a Theory of Sociotechnical Change. Cambridge, MA.

Consul No. 67 (1899). Long Island Pioneer Path, in: L. A. W. Bulletin and Good Roads 29/4, 27.01.1899, p. 121.

Dando, C. E. (2018). Women and Cartography in the Progressive Era. New York, NY.

Dauncey, H. (2012). French Cycling: A Social and Cultural History. Liverpool, England.

Friss, E. (2015). The Cycling City. Bicycles and Urban America in the 1890s. Chicago, IL.

Guroff, M. (2016). The Mechanical Horse: How the Bicycle Reshaped the Americal Life. Austin, TX.

J. W. (1881). Not All a Pastime, in: The Wheel 1/26, 14.09.1881, p. 204.

League of American Wheelmen Official Department (1902). Just Before We Meet, in: Good Roads Magazine 32 (old series), 2/9 (new series), pp. 24-28.

Lessing, H. - E. (2017). Das Fahrrad. Eine Kulturgeschichte. Stuttgart, Germany.

McCullough, R. L. (2015). Old Wheelways. Cambridge, MA.

McLuhan, M. (1992). Die magischen Kanäle. Understanding Media. Düsseldorf, Germany/Wien, Austria.

Münker, S. and Rösler, A. (2008). Vorwort, in: ead. (eds.), Was ist ein Medium? Frankfurt a. M., Germany, pp. 7-12.

N. N. (1881). Editorial, in: Bicycling World and Archery Field 2/2, 21.01.1881, p. 105.

N. N. (1882a). Sign-Boards, in: The Bicycling World 5/5, 30.06.1882, p. 411 .
N. N. (1882b). Wheel Club Doings, in: The Bicycling World 2/15, 18.02.1882, p. 232.

N. N. (1883). The League Stencil, in: The Wheel 4/20, 17.08.1883, p. 1.

N. N. (1894). Don't Get Into a Rut, in: Good Roads 5/6 (June 1894), p. 227.

N. N. (1899). An Elevated Cycleway, in: L. A. W. Bulletin and Good Roads 29/1, 06.01.1899, pp. 17-18.

N. N. (1902). Bicycles as Road Rollers, in: The Bicycling World and Motorcycle Review 45/3, 17.04.1902, p. 91.

Norcliffe, G. (2001). Ride to Modernity: the Bicycle in Canada, 1869-1900. Toronto, Canada.

Norcliffe, G. (2015). Critical Geographies of Cycling: History, Political Economy and Culture. Burlington, VT.

Osborne, L. A. (1899a). Surveying With Bicycle and Cyclometer, in: The Mechanic Arts Magazine 4/3, pp. 100-105.

Osborne, L. A. (1899b). The Bicyclist as a surveyor, in: L. A. W. Bulletin and Good Roads 30/2, 02.09.1899, pp. 124-128.

Potter, I. B. (1898). Cycle Paths. Boston, MA.

Pratt, C. (1894). Dress and Convenienes, in: id. (ed.), What and Why. Some Common Questions Answered. Boston, MA, p. 58.

Quinn, S. C. (1968). The League of American Wheelmen and the Good Roads Movement 1880-1902. [s. 1.].

Raymond, C. T. (1894). Side Paths, in: Good Roads 6/5, 05.11.1894, pp. 263-269.

Reid, C. (2015). Roads were not Built for Cars. Washington, DC.

Smith, R. A. (1972). A Social History of the Bicycle. New York, NY.

Telzah (1882). Some New Hampshire pork, in: The Wheel 2/11, 15.02.1882, pp. 85-86.

Thielmann, T. (2016). Linked Photography. A Praxeological Analysis of Augmented Reality Navigation in the Early $20^{\text {th }}$ Century, in: Cruz, E. G. and Lehmuskallio, A. (eds.), Digital Photography and Everyday Life. Empirical Studies on Material Visual Practices. London, England, pp. 160-185.

Zimmermann, C., Mahlerwein, G. and Maldener, A. (2018). Einleitung: Landmedien und mediale Bilder von Ländlichkeit im 20. Jahrhundert, in: Jahrbuch für Geschichte des ländlichen Raumes 15, pp. 7-19. 